\title{
Experts call for health infoway "watchdog"
}

$\mathrm{D}$ ismal Canadian progress in the development of national electronic health records, as evidenced by a recent report on ehealth from the World Health Organization (WHO) that ranks Canada 21st in information technology development, underscores the need for an independent, national "watchdog" to assess government ehealth efforts, experts say.

"From an accountability perspective, the public should have some awareness that we're not as far along as we would like to be or as they think we are. And secondly, that somebody is paying attention and making sure that we are progressing in the right direction and at a reasonable pace," says Dr. Brian Postl, dean of medicine at the University of Manitoba in Winnipeg and chair of the Canadian Institute for Health Information (CIHI) board of directors. "I believe that's what the public deserves."

Louis Barré, CIHI vice-president (strategy, planning and outreach) argues that Canada must adopt new and better measures to track and assess national ehealth efforts in order to ensure that the national investment in ehealth properly addresses "the real paucity of clinical systems" that currently exists, as well as long-term strategic issues such as the need to ensure that ehealth systems can be employed for medical research. "We are going to need to have a better sense of where we are at now, to build out a meaningful strategy."

Postl and Barré advocate the commissioning of an independent body to assess and report on government efforts - perhaps with arm's-length assistance and funding from an agency or department such as CIHI, the Canadian Institutes of Health Research (CIHR) or the Health Council of Canada.

There's a need for better tracking and monitoring of ehealth by analysts independent of government, concurs Dominic Covvey, president of the National Institutes of Health Informatics (NIHI), a Canada-wide network of 151

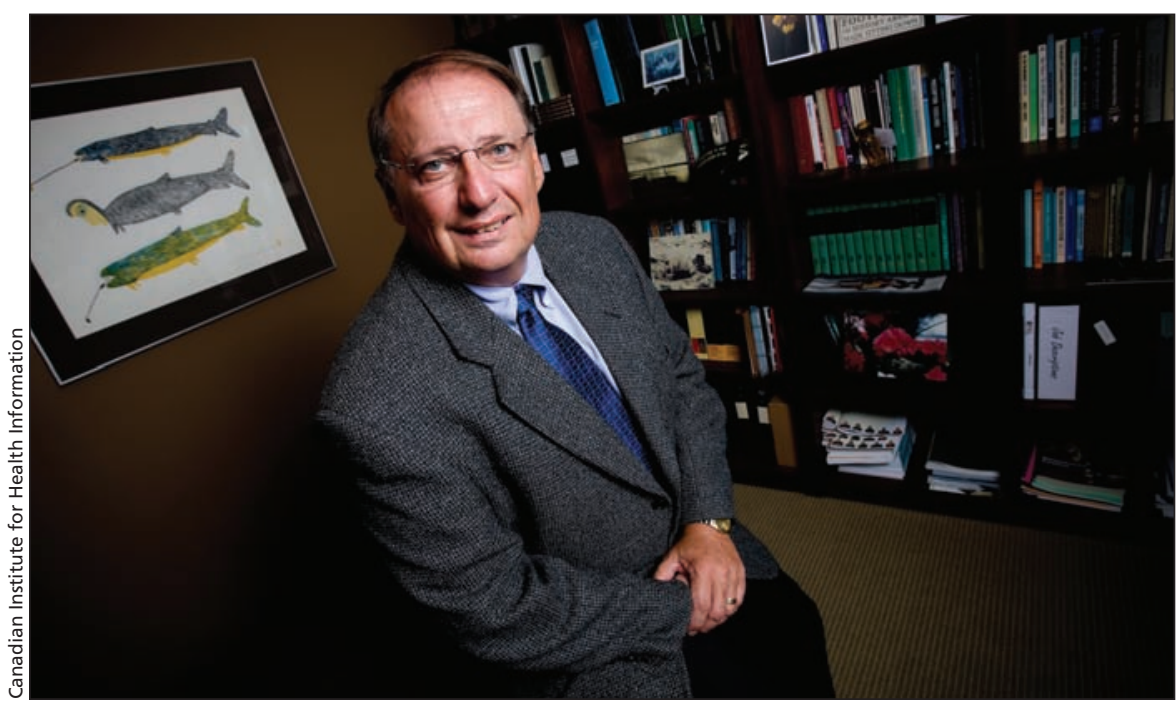

Canada's progress in the development of a national electronic health record system has been "very slow" and "pretty incomplete," says Dr. Brian Postl, dean of medicine at the University of Manitoba in Winnipeg and chair of the Canadian Institute for Health Information board of directors.

ehealth researchers who collaborate within a "virtual institute of institutes."

Canada needs an ehealth "watchdog," says Covvey, who notes that Canada Health Infoway, the federal ehealth agency, faces growing criticism for strategies that have left the nation trailing other nations in ehealth development, despite 17 years of planning and at least $\$ 4$ billion in federal and provincial spending.

"Infoway has no evaluation mandate," Covvey adds, charging that any evaluation of ehealth performance that occurs within Canada Health Infoway amounts to little more than "government evaluating itself."

Robyn Tamblyn, health informatics researcher at McGill University in Montréal, Quebec and leader of a CIHR-funded team that investigates the use of ehealth technologies to support integrated care for chronic disease, says the recent WHO snapshot suggests that a much closer look at Canada's ehealth policies and progress is now warranted.

By providing impartial information, a current state assessment will allow policy-makers to substantiate official claims, Tamblyn argues. A thorough assessment will also help steer ehealth development toward patient-centred solutions and foster such innovation, she argues. "Policies are needed to support research and translation of local successful initiatives [within] a "bottom-up' approach."

"To avoid unnecessary political wrangling," Tamblyn recommends the effort be conducted under the rubric of the CIHR in order to achieve "objective, systematic collection of empirical information."

The calls for an independent assessment of Canada's ehealth efforts follow in the wake of the WHO report that ranked Canada 21st in terms of information technology progress among 159 nations - just ahead of Estonia, but well behind much of Scandinavia, Europe, and the Republic of Korea (www.who.int /goe/publications/goe_atlas_2010.pdf).

The report, ATLAS eHealth country profiles, concludes that Canada's ehealth deficiencies include a lack of supportive federal laws and regulations, national procurement and technology policies, educational policies and scholarships, and evaluations to monitor progress on important areas such as the 
capacity to deliver health information to patients via mobile telephones.

The WHO snapshot of Canada is "worrisome," says Postl. "It's been very slow progress and remains pretty incomplete."

Among the alarming indicators in WHO's profile of Canada, Postl says, are a set of barriers to elearning within medical education at a time when "we've got a gap between the expectations and growing skill sets of our students who now live and breathe in the electronic world by second nature, and our educational systems that are kind of catching up. ... The students know they can't provide effective and safe care with the paper and pencil system where charts disappear."

The WHO profile indicates the time has come for a much more detailed and comprehensive review of Canada's ehealth status, he adds.

Canadians are often "stunned" to discover that basic health information technologies are unavailable, Postl argues. "I think the public thinks that much more exists than actually does exist."

"Do we know what is happening? The answer is no," says Barré. "A current state assessment would be very helpful."

Infoway has struggled to meet such goals as a commitment to ensure that health professionals have access to health records for $50 \%$ of Canadians by 2010 . Kirk Fergusson, Infoway's vice president, corporate affairs, told CMAJ in January that the goal has been achieved for $49.3 \%$ of Canadians. But he did not respond to a request for a data breakout to elucidate how that figure was derived.

Tamblyn argues that Canada also needs to develop an ambitious new basket of national policies to galvanize ehealth progress. The policies should facilitate timely clinical informationsharing between providers in all settings, make personal health records and self-management tools accessible, enable reimbursement for evisits, enable interdisciplinary teamwork and provider consultation, establish incentives for using electronic reminders for preventive care and personalized health care, and implement patient outcomebased financial incentives, she says.

Canada Health Infoway declined to comment on the WHO atlas and referred questions to Health Canada.

David Thomas, spokesman for Health Canada, says "the timing of the WHO survey in 2009 coincided with advance planning for H1N1, a public health priority in Canada, so unfortunately not all of the provinces and territories were able to provide input to the survey. In addition, as with any survey, there are limitations, which include the interpretation and applicability of the questions."

Thomas also notes that "ehealth applications were difficult to assess, and the responses provided may not apply equally across the country." - Paul Christopher Webster, Toronto, Ont.

CMAJ 2011. DOI:10.1503/cmaj.109-3783

\section{The centralized approach to guidelines development}

$\mathrm{T}$ he landscape of clinical practice guidelines development in Canada might best be described as fragmented. There is no central source that funds or coordinates guidelines development across the country. Guideline writers can attempt to secure funding from the government, though their chances of success are slim, so instead they turn to private donors or, in most cases, to disease-specific medical societies, many of which pay the bills with money from pharmaceutical companies or medical device manufacturers.

Though some other countries have a similar scattershot approach to medical knowledge translation, there are a few that consider clinical guidelines a national priority, or at least worthy of a central coordinating body. In the United Kingdom, for example, the National Institute for Clinical Evidence (NICE), established in 1999 to provide clinical guidance to the National Health Service, has a clinical guideline program that is "one of the largest, most productive and best organized developers of clinical guidelines in the world," according to the World Health Organization (www.euro.who.int/_data/assets /pdf_file/0003/96447/E89740.pdf).

Some Canadian experts in medical knowledge translation wonder if Canada should also adopt a centralized approach to guidelines development.

"Aside from the Canadian Task Force on Preventive Health Care, there is little public funding for guideline development in Canada. Many guideline panels have relied on industry (and continue to do so). This is problematic because it creates an obvious potential for conflict of interest," Dr. Gordon Guyatt, professor of clinical epidemiology and biostatistics at McMaster University in Hamilton, Ontario, writes in an email.

"Whether Canada should have a NICE equivalent that itself produces guidelines, I'm not sure," writes Guyatt, a leading proponent of evidencebased approaches to clinical care. "This may be the best approach, but an alternative would be a funding/oversight body that would support groups that wish to do guidelines."

Until the day a central body is estab- lished, if that day ever arrives, researchers who want to fill in gaps in clinical knowledge will be on their own. Anna Taddio, associate professor of pharmacy at the University of Toronto in Ontario, knows that all too well, having recently led the development of a set of guidelines for reducing the pain of childhood vaccination (www.cmaj.ca /cgi/doi/10.1503/cmaj.101720).

Most guideline writers, except those backed by a well-funded specialty society, must cobble together scraps of funding from various sources - asking for $\$ 5000$ here, $\$ 5000$ there. Taddio was able to secure some money from the Canadian Institutes of Health Research (CIHR). For the knowledge translation part of her guidelines, she sought dissemination monies from the Public Health Agency of Canada. No luck.

"We were told that's not covered as a grantable item," says Taddio. "We used only CIHR money and free time."

In the United States, as in Canada, guidelines come from numerous organizations. According to the Guidelines International Network, about $80 \%$ of 